\title{
Effects of Birth-Related Events on Blood Flow Distribution
}

\author{
HARRIET S. IWAMOTO, DAVID TEITEL, AND ABRAHAM M. RUDOLPH \\ Cardiovascular Research Institute, Departments of Physiology, Pediatrics, and Obstetrics, Gynecology, and \\ Reproductive Sciences, University of California, San Francisco, San Francisco, California 94143
}

\begin{abstract}
At birth, the cardiovascular system changes dramatically; arterial blood pressure, heart rate, and cardiac output increase, and blood flow distribution undergoes regional changes. To determine whether these changes are related to certain events occurring at birth, we studied 18 chronically instrumented fetal sheep at 133-138 days gestational age. We measured fetal vascular pressures and heart rate and injected radionuclide-labeled microspheres to determine combined ventricular output and its distribution. Rhythmic ventilation of the fetuses with a gas mixture that produced no change in arterial blood gases decreased heart rate slightly from $173 \pm 25$ to $152 \pm 16$ beats/min, but changed neither mean arterial blood pressure nor combined ventricular output. Ventilation with oxygen decreased mean descending aortic and pulmonary arterial pressures, but had no significant effect on heart rate or combined ventricular output; subsequent umbilical cord occlusion had no significant effect on these variables. There was a redistribution of blood flow, however. Ventilation alone increased pulmonary blood flow from $159 \pm 68$ to $641 \pm 513 \mathrm{ml} \cdot \mathrm{min}^{-1} \cdot 100 \mathrm{~g}$ wet weight ${ }^{-1}$, and oxygenation increased it further to $1040 \pm 426$. Ventilation alone and ventilation with $\mathrm{O}_{2}$ decreased blood flow to most other fetal organs, notably the adrenal glands, brain, and heart, in a manner related to changes in arterial oxygen tension. Occlusion of the umbilical cord increased blood flow to the adrenal glands and brown fat, and also to the liver from the portal vein and hepatic artery. The changes in regional blood flow initiated by ventilation, oxygenation, and umbilical cord occlusion are similar to those occurring at birth and may play an important role in postnatal adaptation. (Pediatr Res 22: 634-640, 1987)
\end{abstract}

The transition from intrauterine to extrauterine existence is marked by a number of events, including uterine contractions, delivery, physical expansion of the lungs, increases in blood oxygen tension and content, the removal of the placenta from the circulation, and transfer from a warm-fluid to a cool-air external environment. Dramatic changes occur in the circulation, among which are increases in cardiac output, heart rate, and arterial blood pressure $(1,2)$. Many previous studies designed to examine the transition period have been conducted in anesthetized, acutely exteriorized, and often open-chest preparations of fetal sheep, in which "birth" is designated as the moment the umbilical cord is cut (3-7). These preparations are unstable and often have cardiovascular and metabolic variables markedly different from those obtained from chronically prepared fetuses

Received February 13, 1987; accepted July 29, 1987.

Correspondence and reprint requests Harriet S. Iwamoto, Ph.D., Box 0544, HSE 1403, University of California, San Francisco, San Francisco, CA 94143.

Grant HL35842 from the U.S. Public Health Service. studied in utero. A few studies have been conducted in chronically prepared fetuses undergoing spontaneous labor and delivery $(8,9)$, but because many events occur at once, it is difficult to determine the precise cause of an observed response. Recently, the effects of ventilation $(10,11)$ and of cooling $(12,13)$ have been examined in chronically maintained preparations of fetal sheep.

To determine which specific perinatal events cause the changes in the cardiovascular system that occur at birth, we examined the sequential effects of mechanical ventilation of the lungs, oxygenation, and umbilical cord occlusion without the additional effects of other perinatal events. We studied chronically prepared sheep fetuses that were allowed to recover from anesthetic and surgical stress and measured heart rate, arterial pressure, and combined ventricular output and its distribution by the radionuclide-labeled microsphere method.

\section{METHODS}

Animals and surgical preparation. We studied 18 fetal sheep at 133-138 days gestational age. Fourteen fetuses were prepared with catheters only at 131-134 days, and four were prepared with catheters and an electromagnetic flow transducer placed around the ascending aorta at 133-136 days.

The ewe was fasted for 24-36 h prior to surgery. Spinal or low epidural anesthesia was achieved by injecting $4 \mathrm{ml}$ of $1 \%$ tetracaine hydrochloride (Pontocaine $\mathrm{HCl}$, Breon Laboratories, New York, NY). Polyvinyl catheters (1.3 $\mathrm{mm}$ inner diameter, $2.3 \mathrm{~mm}$ outer diameter) were placed into the descending aorta and inferior vena cava of the ewe via a pedal artery and vein. Ten percent dextrose in $0.9 \% \mathrm{NaCl}$ were infused continuously, and 50-100 mg of ketamine hydrochloride (Vetalar, Parke-Davis, Morris Plains, NJ) were administered intravenously at 15 -min intervals throughout the duration of the surgical procedure; additional amounts were administered when necessary. Local anesthesia $(0.25 \%$ lidocaine hydrochloride) was applied prior to each fetal skin incision.

A midline incision was made in the abdomen of the ewe, and the pregnant horn of the uterus was exposed. A fetal hindlimb was exposed through a small incision in the uterus; polyvinyl catheters $(0.75 \mathrm{~mm}$ inner diameter, $1.2 \mathrm{~mm}$ outer diameter) were inserted into a pedal artery and vein and advanced so their tips lay in the descending aorta and inferior vena cava. Through the same uterine incision, two polyvinyl catheters $(3.5 \mathrm{~F})$ were advanced into a main umbilical vein from a peripheral tributary, and one (1.3 $\mathrm{mm}$ inner diameter, 2.3 outer diameter) was placed in the amniotic cavity. The fetal skin and uterine incisions were sutured.

A second uterine incision was made overlying the left chest of the fetus. Through a thoracotomy in the fourth intercostal space, catheters were placed in the ascending aorta from the internal thoracic artery $(0.75 \mathrm{~mm}$ inner diameter, $1.2 \mathrm{~mm}$ outer diame- 
ter), and directly into the left atrium. pulmonary artery (20) gauge IV cath. Becton Dickinsom. Mountain View, ( A). and pleural cavity. In four fetuses, a cuff-type electromagnetic flow transducer with an inner diameter approximately 90$)^{\prime}$ of the vessel diameter was placed around the ascending aorta just above the origin of the coronary arteries ( $($ and (' Instruments. Pasadena. ( $A$ ). The flow transducers were precalibrated in vitro: we have shown that this calibration is within $5 \%$ of that measured in intact lambs (14). During an experiment, the electrical zero was checked repeatedly: ere flow was recorded as the absence of flow during the diastolic phase of the cardiac cycle. The fetal chest was sutured in layers. The fetal neck was exposed through the same uterine incision. $\wedge$ 4.5-mm endotracheal tube was connected by a $Y$-tube to two $100 \mathrm{~cm}$ lengths of flexible poly iny tubing ( $3.2 \mathrm{~mm}$ inner diameter. 6.4 outer diameter). The tubing was filled with $0.9 \%$ saline, and the trachea was intubated. $A$ polyvinyl aatheter was inserted into the external jugular vein and advanced centrally to the superior sena cara. 1 second catheter was placed in the amniotic cavity and comnected to the ventilation tubing to allow trachea fluid to flow freely from the fetus to the amniotic cavity postoperatively. An inflatable silicone rubber cuff, which did not constrict the umbilical vessels when deflated. was placed around the umbilical cord at the umbilical ring. All incisions were sutured. the vascular catheters were filled with heparin sodium solution $(1000) \mathrm{J} / \mathrm{ml})$ and seated, and all catheters and ventilation tubing were exteriorized to the maternal flank and protected by a cloth pouch. Antibiotics (40) mg Kanamycin, I million I penicillin) were given into the amniotic cavity and maternal vein on the day of surgery and each day thereafter. The animals were allowed 2 to 3 days to recover from surgery.

Experimental procedure. On the day of the study. the ewes were brought into the laboratory in a mobile cart and allowed to become accustomed to the surroundings for at least $2 \mathrm{~h}$. fetal blood pressures were monitored continuously throughout the experimental period, using Statham P2.3Db strain-gatuge transducers, and Beckman R612 and (iouk 280$)$ S polvgraphs. Fetal heart rate, measured by a cardiotachometer which was triggered by an arterial pulse wave, also was monitored continuousls Measurements were made in the fetuses 1) during the control period and $15 \mathrm{~min}$ after the onset of each of the following conditions: 2) ventilation with $3 \%(), 5 \%(0)$, and $92 \%$ (ventilation). 3) ventilation with $100 \%$ oxygen (oxygenation). and 4) ventilation with oxygen following umbilical cord compression (occlusion). Blood samples were obtained from the descending aorta for the determination of $\mathrm{pH}, \mathrm{P}\left(\mathrm{O}_{2}\right.$ and $\mathrm{PC} \mathrm{C}^{\circ}$, and from the ascending and descending aorlat. pulmonary artery. umbilical vein, and left atrium for the determination of the hemoglobin concentration and blood oxygen saturation (model 1.58 Blood (ias Analyzer, (orning Medical. Medfield. MA: model ()SM? Hemoximeter, Radiometer, (openhagen. Denmark). (ombined ventricular output and blood llow distribution then were determined by injecting two differently labeled $15 \mu \mathrm{m}$ microspheres

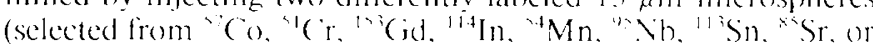
"Zn; New lingland Vuclear. Boston. MA) inte the inferior vena cava and left atrium while obtaining reference samples at a rate of $4 \mathrm{ml} / \mathrm{min}$ from the descending and ascending artat and the pulmonary artery. The volume of blood removed for the blood and reference samples was replaced with an equal volume of fetal donor or. in rare instances. maternal blood. To ventilate the fetuses, the tubes connected to the endotracheal tube were opened and tracheal fluid was allowed to drain. These tubes were connected to a specially designed positive pressure ventilator. into which a gats mixture consisting of $33^{\prime \prime} ;\left(0.55^{\prime} ;()_{2}\right.$. and $92{ }^{\prime \prime} ;$ $\mathrm{N}$, was introduced at a rate of $10-15 \mathrm{liter} / \mathrm{min}$ (Fig. 1). (On inspiration, gas flowed from the pump through the tubing and into the fetus. On expiration, a solenoid in series with the expiratory tubing opened, and the expired air from the fetus was flushed from the lubing to the outside. This overcame the possible difficulties of a large dead space for ventilation. We were able to control the rate of respiration, inspiratory and end expiratory pressures: these values and didat rolume, which was measured by a pneumotachograph (l\%eisch type no. (0). Nedical Inc.. Richmond VA: Validyne model DP45-16 pressure transducer and model (I) 15 carrier demodulator. lingincering (orp. Vorthridge, (A), were as shown in Table 1. There were no significant changes in these variables throughout the experimental period.

I pon completion of the last set of measurements, the cwe was anesthetized with an intravenous injection of $6-10 \mathrm{~g}$ sodium pentobarbital (Futhanasia-6. Veterinary I aboratories. I exena. KS) and killed with an intravenous injection of saturated potatssium chloride solution. (ombined ientricular output and its distribution were determined as described previously in detail (15). Briefly, the uterus and individual fetal organs were dissected. weighed, and placed in formalin. Organs were carbonized in an oven at $350^{\circ}$, ground into a coarse powder placed into plastic vials to a uniform height of $3 \mathrm{~cm}$. and counted in a $100($ )-channel multichannel pulse-height analyer (Norland (orp. Fort Atkinson. WI). The activity of ach isotope in cach organ was determined by the kast-squares method described previously (16).

Datu andlysis. Blood flow to fetal organs was calculated in the control period by comparing the radioactivity of the microsphere injected into the inferior vena cava in each organ with the radioactivity and flow rate of the appropriate reference sample fascending aorta for upper body organs. descending aorta for lower body organs. pulmonary artery for lungs). as described previously in detail (15). After the fetuses were sentilated. pulmonars blood flow and blood flow through vascular shunts characteristic of the fetal circulation were altered dramatically. Therefore, blood tlow to fetal organs was cakculated using the radioactivity of the microspheres injected into the left atrium for ventiation. oxygenation. and occlusion measurements. Because central blood flow patterns were altered dramatically by ventilattion. combined ventricular output and pulmonary blood thow were calculated by a series of equations to be presented elsewhere (17).

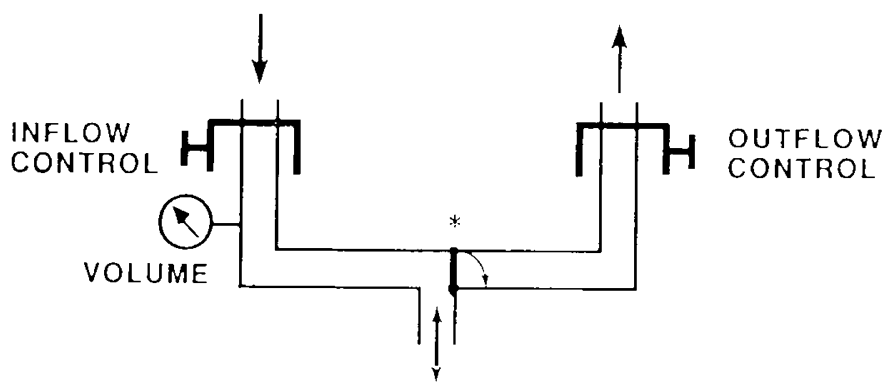

TRACHEA

Fig. I. Ijagram of the positice pressure ventilator used in these studies. (jas of known composition was introduced into the contilation tubing. Respiratory rate and inflow and outtlow rates and thus inspirattory and experatory pressures. were each controlled independently a solenotd. indicated by the avertik is shown in the position durins: inspiration. On expiration. the solenoted opened. and the expleded gas from the fetus was tlushed through the tubing to the amospinete

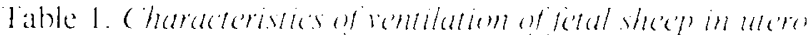
mes $(l n \pm . S \%)$

Respiratory rate $(/ \mathrm{min})$ Ventilation Ongenation ()ectusion $50 \pm 9 \quad 5+10 \quad 50+12$

Peak inspiratory pressure $\quad 27 \pm 10 \quad 25 \pm 10 \quad 25 \pm 8$ $(\text { lorr })^{*}$

Find expiratory pressure $(\mathrm{tor} t)^{*}$

Ventilatory volume (m)

$\therefore \pm^{-} \quad 5+\cdots$

$n$

$24+15 \quad 37 \pm 16 \quad 31+11$

* Amniotic cavity pressure is cero reference for these pressures. 
Vascular pressures were corrected using amniotic fluid pressure as zero reference. Oxygen contents were calculated by multiplying the oxygen saturation of the blood times the hemoglobin concentration by 1.35. During oxygenation and occlusion, the amount of dissolved oxygen was calculated from the $\mathrm{PO})_{2}$ of the blood and was added in calculating oxygen content. Data from one period were compared with data from the previous period by the Mann-Whitney $\mathrm{U}$ test. with the understanding that the chance of committing a type II error with paired data is increased. Unless otherwise stated. $n=14$ for control, ventilation, and oxvgenation measurements. and $n=10$ for occlusion measurements, because in two animals the umbilical cord occluder did not function properly. and two other animals developed a pneumothorax before occlusion measurements were made. All data are expressed as mean $\pm \mathrm{SD}$.

\section{RESULTS}

In carly attempts to determine the effects of birth-related events on left ventricular output in the fetus, we placed an electromagnetic flow transducer around the ascending aorta of four fetal sheep. During the control period, there was no significant difference between mean pressures in the ascending and descending aorta and pulmonary artery (Table 2). However. systolic and pulse pressures in the ascending aorta were slightly greater than those in the descending aorta and pulmonary artery. Ventilation increased mean. systolic. diastolic. and pulse pressures in the ascending aorta in fetuses with flow transducers, but not in those without flow transducers (Tables 2 and 3 ). Oxygenation increased these pressures only in fetuses with flow transducers. Changes in descending aortic and pulmonary arterial pressures were not as pronounced (Table 2). Twenty min after ventilation had ceased and the umbilical cord occluder had been released, pressures in the ascending aorta and left ventricular output decreased simultancously. There were no such associations between pressures in the descending aorta or pulmonary artery and left ventricular output. As a result of these observations, we did not use a flow transducer to measure left ventricular output in subsequent studies, and the remainder of the data presented were obtained from the 14 animals in which only catheters were implanted and blood flows were measured with microspheres.

Fetal body weight for the 14 fetuses was $3.61 \pm 0.64 \mathrm{~kg}$ (range $2.53-4.45 \mathrm{~kg}$ ). During the control period. values for pH. $\mathrm{PO}_{2}$. and $\mathrm{PCO}_{2}$ in the descending aorta and blood saturation and $\mathrm{O}_{2}$ content in the descending aorta. ascending aorta. left atrium. pulmonary artery, and umbilical vein were within the expected

Table 2. Arterial blood pressures in four animals with electromagnetic flow transducers around ascending aorta /tort

\begin{tabular}{|c|c|c|c|c|}
\hline \multirow{2}{*}{-} & \multicolumn{3}{|c|}{$\left.\left(m^{\prime}(a n \pm S I)\right)\right]$} & \multirow{2}{*}{ Occlusion } \\
\hline & Control & Ventilation & Oxygenation & \\
\hline \multicolumn{5}{|c|}{ Descending aortal } \\
\hline Mean & $57 \pm 4$ & $57 \pm 7$ & $57 \pm 5^{*}$ & $53 \pm 3$ \\
\hline Systolic & $76 \pm 8$ & $79 \pm 10$ & $71 \pm 9$ & $68 \pm 9$ \\
\hline Diastolic & $46 \pm 3^{*}$ & $44 \pm 7$ & $48 \pm 6 \dagger$ & $45 \pm 3$ \\
\hline Pulse & $30 \pm 8$ & $35 \pm 8$ & $23 \pm 4^{*}$ & $23 \pm 8$ \\
\hline \multicolumn{5}{|c|}{ Ascending aorta } \\
\hline Mean & $57 \pm 6$ & $62 \pm 6$ & $68 \pm 3 \dagger$ & $64 \pm 11$ \\
\hline Systolic & $80 \pm 16$ & $85 \pm 10 \dagger$ & $98 \pm 14 \dagger$ & $87 \pm 16$ \\
\hline Diastolic & $43 \pm 4$ & $45 \pm 7$ & $50 \pm 5 t$ & $47 \pm 9$ \\
\hline Pulse & $37 \pm 13$ & $41 \pm 8^{*}$ & $49 \pm 10 \div$ & $40 \pm 9$ \\
\hline \multicolumn{5}{|c|}{ Pulmonary artery } \\
\hline Mean & $58 \pm 3$ & $62 \pm 10$ & $58 \pm 13$ & $50 \pm 11$ \\
\hline Systolic & $74 \pm 7$ & $74 \pm 11$ & $73 \pm 13$ & $62 \pm 6$ \\
\hline Diastolic & $47 \pm 2$ & $49 \pm 10$ & $48 \pm 12$ & $40 \pm 16$ \\
\hline Pulse & $27 \pm 5$ & $25 \pm 4$ & $25 \pm 8$ & $22 \pm 10$ \\
\hline
\end{tabular}

$* p<0.05$

$+p<0.005$. significantly different from values obtained from fetuses with no flow transducer placed around the ascending aorta (Table 3).
Table 3. Effects of birth-related events on fetal heart rate and arterial blood pressures (mean $\pm S D$ )

\begin{tabular}{lcccc} 
& Control & Ventilation & Oxygenation & Occlusion \\
Heart rate & $173 \pm 25$ & $152 \pm 16^{*}$ & $152 \pm 21$ & $163 \pm 46$ \\
Pressures (torr) & & & & \\
Descending aorta & & & & \\
$\quad$ Mean & $52 \pm 6$ & $53 \pm 6$ & $47 \pm 6^{*}$ & $56 \pm 16$ \\
$\quad$ Systolic & $73 \pm 8$ & $73 \pm 9$ & $65 \pm 6$ & $76 \pm 19$ \\
$\quad$ Diastolic & $40 \pm 5$ & $40 \pm 7$ & $36 \pm 5$ & $45 \pm 12$ \\
$\quad$ Pulse & $33 \pm 6$ & $34 \pm 6$ & $30 \pm 7$ & $28 \pm 14$ \\
Ascending aorta & & & & \\
$\quad$ Mean & $53 \pm 5$ & $55 \pm 7$ & $49 \pm 7$ & $55 \pm 14$ \\
$\quad$ Systolic & $69 \pm 9$ & $69 \pm 8$ & $64 \pm 8$ & $71 \pm 17$ \\
Diastolic & $41 \pm 6$ & $42 \pm 8$ & $37 \pm 7$ & $47 \pm 12$ \\
$\quad$ Pulse & $28 \pm 6$ & $27 \pm 7$ & $27 \pm 6$ & $24 \pm 8$ \\
Pulmonary artery & & & & \\
$\quad$ Mean & $54 \pm 7$ & $55 \pm 9$ & $47 \pm 6^{*}$ & $45 \pm 14$ \\
Systolic & $73 \pm 13$ & $72 \pm 14$ & $64 \pm 7$ & $60 \pm 15$ \\
$\quad$ Diastolic & $42 \pm 5$ & $42 \pm 8$ & $36 \pm 6$ & $34 \pm 15$ \\
Pulse & $30 \pm 10$ & $29 \pm 10$ & $27 \pm 5$ & $26 \pm 11$ \\
\hline
\end{tabular}

* Signifies value different from preceding value. $p<0.05$.

range for fetuses at this stage of gestation (Table 4). Characteristic of the fetal circulation. in which gas exchange takes place in the placenta. umbilical venous oxygen saturation and oxygen content were significantly greater than those in the fetal arteries (Table 4). The umbilical venous-descending aortic oxygen content difference was $2.21 \pm 0.75 \mathrm{mM}$, and the left atrial-pulmonary arterial oxygen content difference was $0.45 \pm 0.36 \mathrm{mM}$. Oxygen content and blood saturation in the ascending aorta were slightly greater than those in the descending aorta. and oxygen content in the descending aorta was slightly greater than in the pulmonary artery. Ventilation of the fetal lungs with a gas mixture consisting of $3 \% \mathrm{O}_{2} .5 \% \mathrm{CO}_{2}$. and $92 \% \mathrm{~N}_{2}$ produced no significant changes in any of these values or relationships. With oxygenation, the site of oxygen uptake shifted almost completely from the placenta to the lungs. The left atrial-pulmonary arterial oxygen content difference increased significantly to $0.95 \pm 0.53$ $\mathrm{mM}(p<0.005)$. and the umbilical venous-descending aortic difference decreased significantly to $0.20 \pm 0.37 \mathrm{mM}(p<0.001)$. a value not different from zero. Blood oxygen saturation and content increased in all vessels $(p<0.001)$ : left atrial and ascending and descending aortic oxygen saturation $(p<0.001)$ and content $(p<0.02)$ were significantly greater than in the pulmonary artery. With oxygenation, the oxygen tension in the carotid and pulmonary arteries, left atrium, and umbilical vein increased to $225 \pm 162(n=14) .50 \pm 3(n=12) .163 \pm 141(n$ $=8)$, and $77 \pm 29$ torr $(n=12)$, respectively. Subsequent umbilical cord occlusion produced no significant changes in these values or relationships.

Fetal heart rate was $173 \pm 25$ beats/min during the control period (Table 4). Heart rate decreased slightly with ventilation alone, but neither oxygenation nor occlusion produced a further significant change. Mean blood pressures in the descending and ascending aorta and pulmonary artery were 52-54 torr during the control period (Table 3 ). There were slight decreases in mean descending aortic and pulmonary arterial pressures with oxygenation, but in general. ventilation. oxygenation. and occlusion produced little change in these values. Pulse pressure in the descending aorta was greater than that in the ascending aorta during the control period $(p<0.05)$. and greater than that in both the ascending aorta and pulmonary artery during ventilation $(p<0.02)$. These findings differ from those obtained from the animals that had a flow transducer placed around the ascending aorta (Table 2).

Combined ventricular output was $398 \pm 81 \mathrm{ml} \cdot \mathrm{min}^{-1} \cdot \mathrm{kg}^{-1}$ during the control period. Ventilation, oxygenation, and occlusion each produced no significant alteration in combined ventricular output. Blood flow to the umbilical-placental circulation 


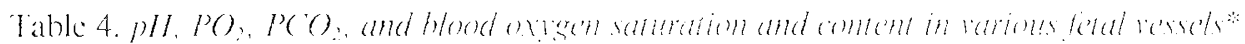

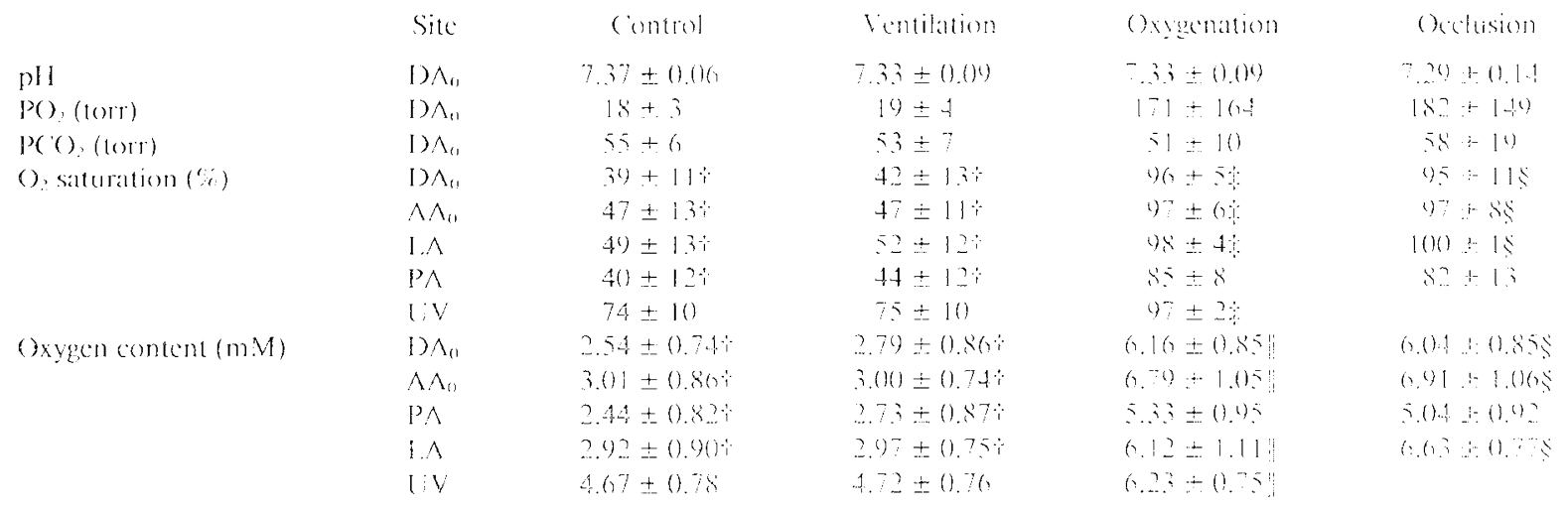

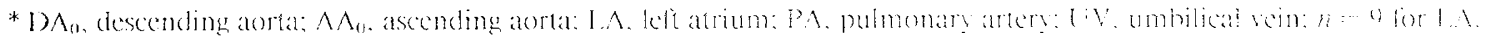
$+p<0.0(0) 1$, significanty different lirom $1 ; \mathrm{V}$ viluc.

$\forall p<0.0(0) . \$ p<0.01 . \| p<0.02$, significantly different from Pl value

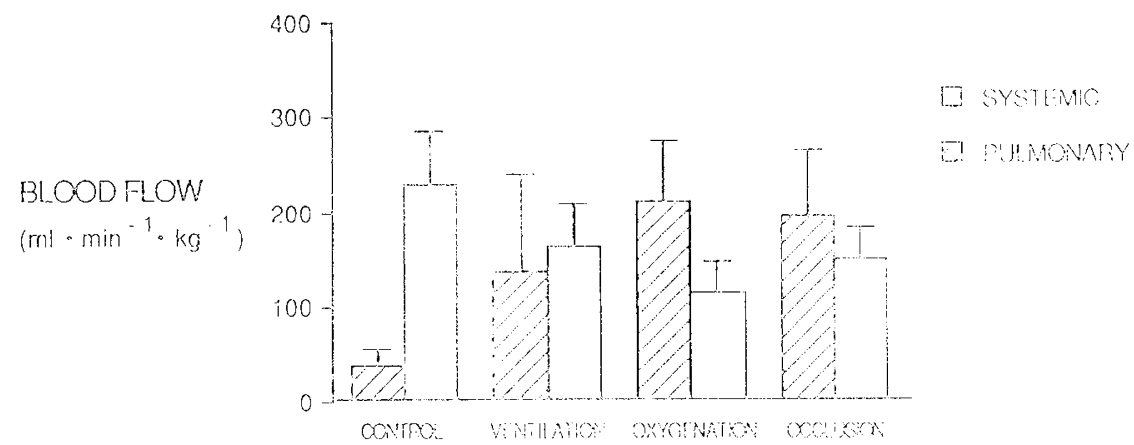

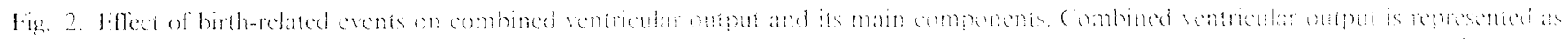

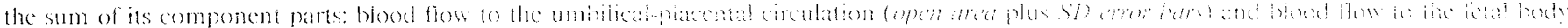

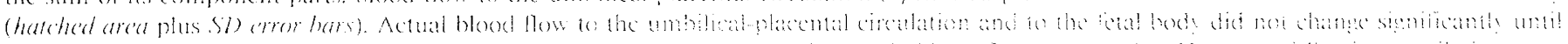

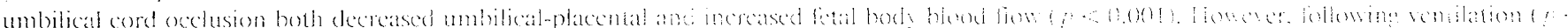

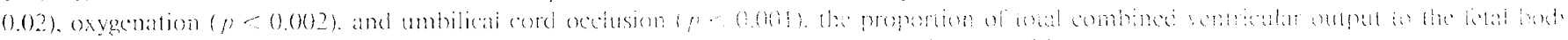

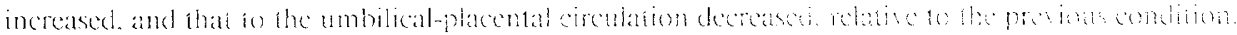

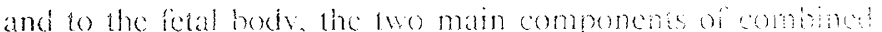
ventricular output were $139+55$ and $259+63$ jol andin se during the control period and comprised 35 and $65 \%$ of wal

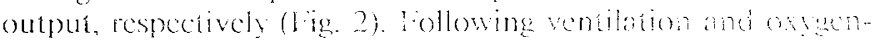

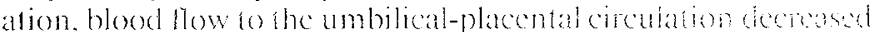

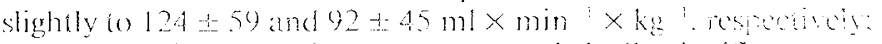
the changes in aciual how were not statsically significan an pame/), but there was a decrease in the perecotage of tomal bew to the umbilical-placental circulation to $29+8$ and $22 \pm 0 \%$ (botfom parnel). Occlusion of the umbilical cord clecreased un bilicalplacental hood flow to $2.3 \div 2.7 \mathrm{ml} \times \mathrm{min}: \times \mathrm{k}:$ indicating complete obstruction of both the artertes and was. Ventilation, oxygenation. and occlusion each slight! ingensed

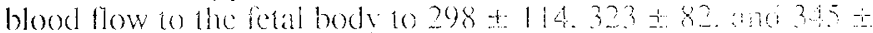
$95 \mathrm{ml} \times \mathrm{min}^{1} \times \mathrm{kg}$ ! respectivels. The increases in actal how were not signiticant. but the increases in the perecntage of iont flow were signilicant.

Despite the relative constancy of total output of blose fom the heart and blood flow to the fetal body there was a significant

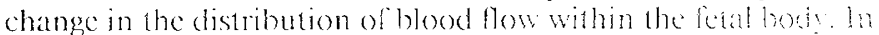

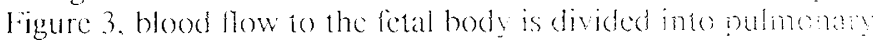
and systemic blood flow. exchusive of umbilical-placental bood flow. During the control period. pulmonary and systemic inoud

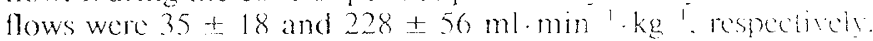
With ventilation. pulmonary blood llow increased by greator than $40(0 \%$ to $135 \pm 104 \mathrm{ml} \cdot \mathrm{min} \cdot \mathrm{kg}$. and systomic boud

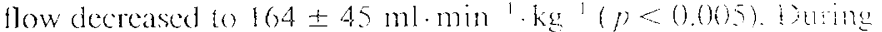
oxygenation. pulmonary blood flow increased lurther to 210.2 $\pm 64.5 \mathrm{ml} \cdot \mathrm{min}$ '. $\mathrm{kg}$ ! and systemic blood flow decreased an

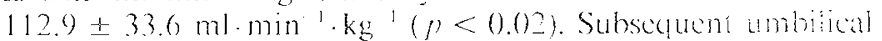

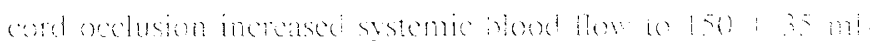

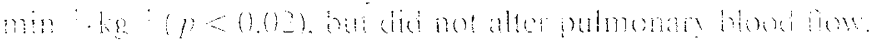

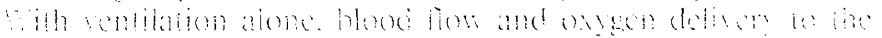

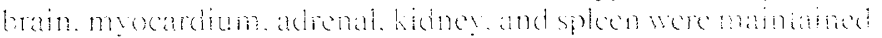

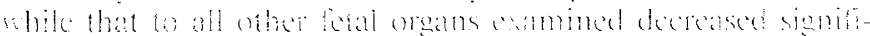

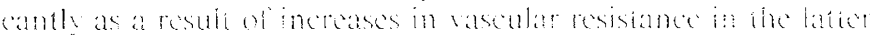

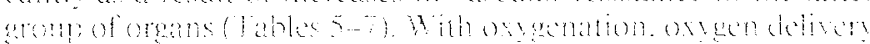

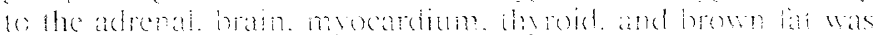

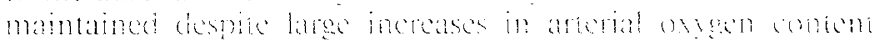

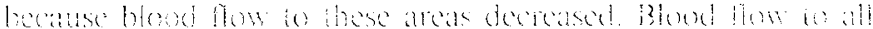

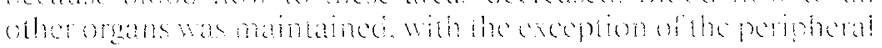

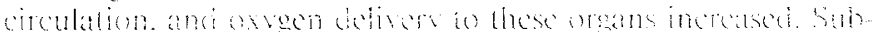

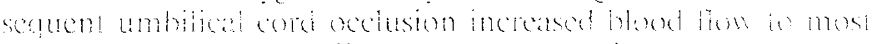

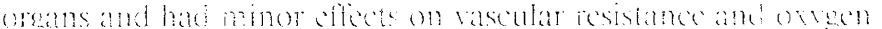

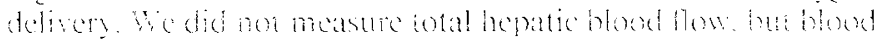

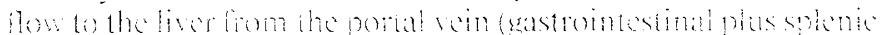

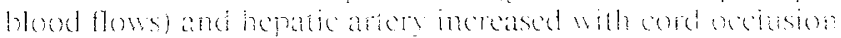

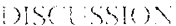

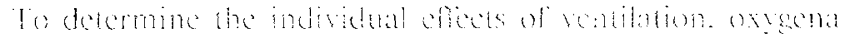

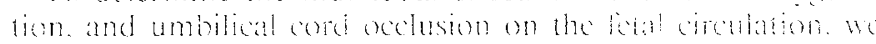

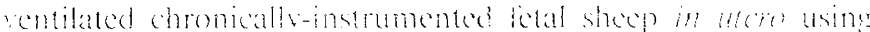

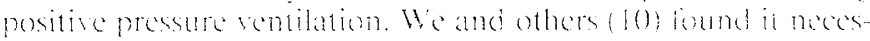

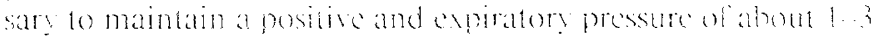

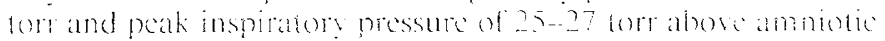
pressure to keen the lunes inflated hecause as shown in Parand

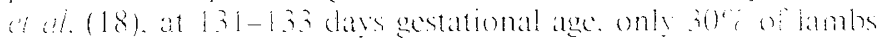

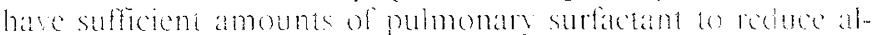
seolar surface temsion and heep the lungs inflated fo the extem 
necessary for survival. The fetuses in our study ranged from 133 138 days gestation and thus would be expected to require relatively high ventilation pressures for effective lung ventilation. During the control period, gas exchange took place in the placenta, and oxygen content was highest in the umbilical vein. During ventilation with oxygen, the lungs became an important site of oxygen exchange as indicated by the significant increase in the left atrial-pulmonary arterial oxygen difference and marked decrease in umbilical venous-descending aortic oxygen difference. The effectiveness of ventilation varied, as indicated by the wide range of $\mathrm{PO}_{2}$ in the descending aorta (35-519 torr). However, ventilation of each fetus was adequate because arterial blood oxygen saturations ranged from $93-100 \%$, and arterial $\mathrm{pH}$ and $\mathrm{PCO}_{2}$ did not change significantly.

In the four fetuses with flow transducers around the ascending aorta, ventilation and oxygenation were associated with increases in blood pressures in the ascending aorta, but not in the descending aorta or pulmonary artery. The increases may be related to the phenomenon described by Goldstein and Epstein (19), who, in a model system, demonstrated that supravalvular aortic stenosis can produce an apparent increase in innominate arterial pressure, but not in distal aortic pressure, and that innominate arterial pressure can increase linearly with left ventricular output. Their explanation is that the stenosis produces a jet stream of blood directed into the innominate artery, and a portion of the kinetic energy is converted to potential energy, which is detectable as increases in systolic and mean arterial pressures in the innominate artery. In our studies, ascending aortic pressure varied with left ventricular output. We conclude that the increase in aortic pressure associated with ventilation is the result of the increased velocity of blood flow across the aortic constriction produced by the flow transducer when left ventricular output increases.

Systemic arterial pressure and heart rate increase after birth (1). In fetuses prepared with catheters only and no flow transducer, we detected no increase in systemic arterial blood pressure
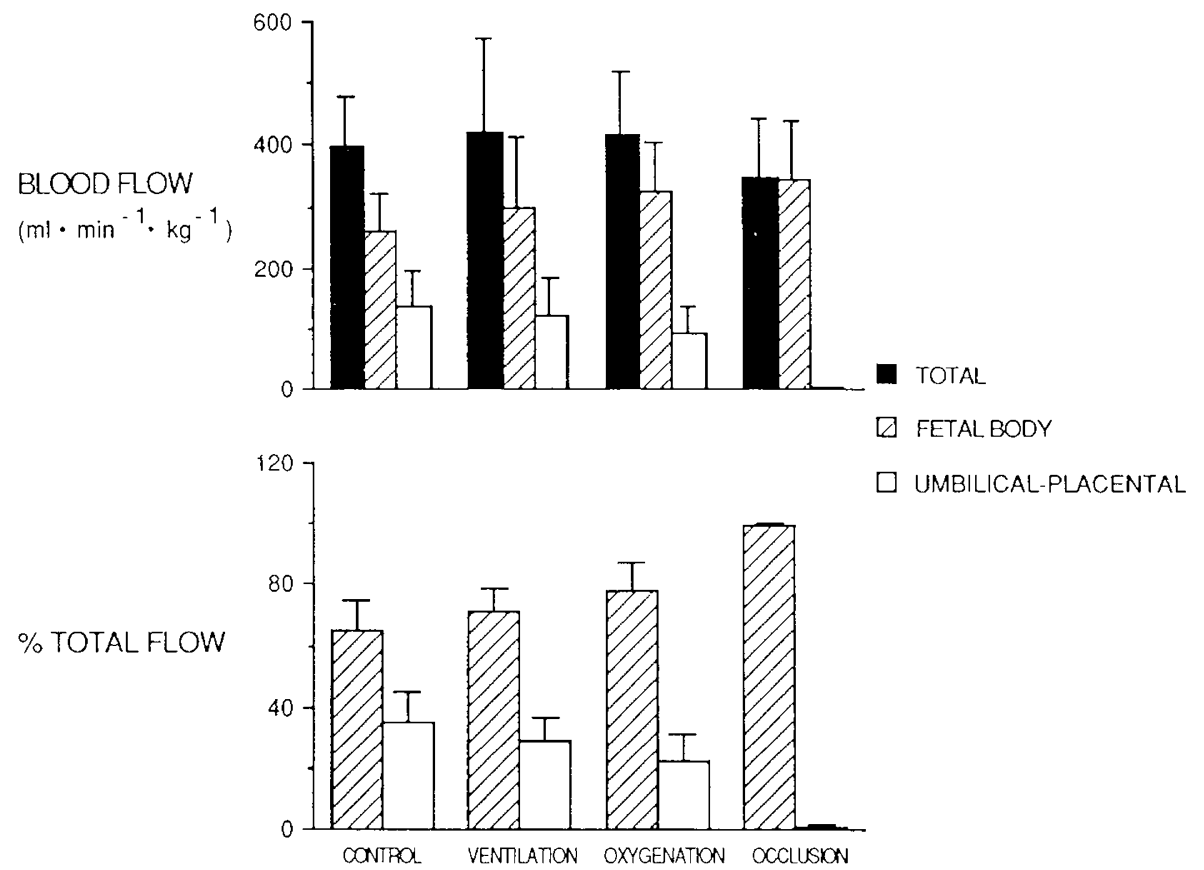

Fig. 3. Effect of birth-related events on systemic and pulmonary blood flows. Blood flow to the fetal body is represented as systemic blood flow (open area plus $S D$ error bars) and pulmonary blood flow (hatched area minus $S D$ error bars). Ventilation $(p<0.005)$ and oxygenation $(p<0.02)$ were associated with an increase in pulmonary and a decrease in systemic blood flows, relative to the previous condition. In addition, cord occlusion significantly increased systemic blood flow $(p<0.02)$.

Table 5. Blood flow $\left(\mathrm{ml} \times \mathrm{min}^{-1} \times 100 \mathrm{~g}^{-1}\right)$ to various fetal organs

\begin{tabular}{lcccc}
\hline \multicolumn{1}{c}{ Organ* } & Control & Ventilation & Oxygenation & Occlusion \\
\hline Adrenal & $397 \pm 170$ & $362 \pm 160$ & $167 \pm 56$ & $223 \pm 75 \dagger$ \\
Brown fat & $66 \pm 37$ & $30 \pm 12 \ddagger$ & $13 \pm 8 \ddagger$ & $26 \pm 12 \dagger$ \\
Kidneys & $245 \pm 69$ & $199 \pm 67$ & $151 \pm 33$ & $164 \pm 50$ \\
Gastrointestinal tract & $94 \pm 28$ & $59 \pm 22 \S$ & $53 \pm 31$ & $83 \pm 34 \dagger$ \\
Spleen & $368 \pm 189$ & $272 \pm 143$ & $279 \pm 85$ & $447 \pm 162 \ddagger$ \\
Liver & $18 \pm 17$ & $15 \pm 18$ & $14 \pm 15$ & $37 \pm 19 \ddagger$ \\
Periphery & $15.3 \pm 3.2$ & $11.1 \pm 4.0 \S$ & $8.1 \pm 3.1 \dagger$ & $9.3 \pm 1.7$ \\
Brain & $151 \pm 49$ & $135 \pm 53$ & $102 \pm 21 \|$ & $94 \pm 59$ \\
LV & $265 \pm 164$ & $238 \pm 126$ & $113 \pm 30 \|$ & $66 \pm 48 \ddagger$ \\
RV & $321 \pm 111$ & $280 \pm 97$ & $120 \pm 65$ \\
Thyroid & $223 \pm 120$ & $116 \pm 51 \S$ & $84 \pm 47$ \\
Lung & $159 \pm 68$ & $641 \pm 513 \|$ & $1040 \pm 426 \ddagger$ & $1005 \pm 479$ \\
\hline
\end{tabular}

* Periphery comprises the skin, muscle, and skeleton of the fetus; LV and RV are left and right ventricular free wall; liver flows represent the hepatic arterial contribution only.

$\dagger$ Denotes a significant change from previous value, $p<0.05$.

$\ddagger$ Denotes a significant change from previous value, $p<0.02$.

$\S$ Denotes a significant change from previous value, $p<0.005$.

$\|$ Denotes a significant change from previous value, $p<0.001$. 
HETAL RESPONSES TO BIRTH-RELATID EVENTS

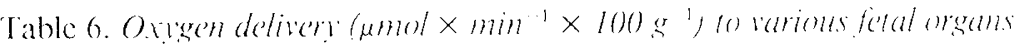

\begin{tabular}{|c|c|c|c|c|}
\hline Organ* & Control & Ventilation & ()xygenation & Occlusion \\
\hline Adrenal & $949 \pm .347$ & $1021 \pm 675$ & $1025 \pm 366$ & $1367 \pm+81$ \\
\hline Brown fat & $167 \pm 1.32$ & $75 \pm .32 \dagger$ & $81 \pm 53$ & $139 \pm 79$ \\
\hline Kidncys & $601 \pm 183$ & $538 \pm 2() 2$ & $936 \pm 275 \|$ & $908 \pm 340$ \\
\hline Gastrointestinal tract & $240 \pm 101$ & $157 \pm 560 t$ & $.28 \pm 200 \%$ & $488 \pm 188$ \\
\hline Spleen & $859 \pm 418$ & $733 \pm 414$ & $1722 \pm 587 \|$ & $26,84 \pm 98885$ \\
\hline Periphery-lower & $37 \pm 12$ & $28 \pm 10 \%$ & $46 \pm 21 \%$ & $56 \pm 2(0)$ \\
\hline Periphery-upper & 49) \pm 25 & $33 \pm 1.34$ & $60 \pm 23 \|$ & $64 \pm 9$ \\
\hline Brain & $4.37 \pm 122$ & $396 \pm 172$ & $381 \pm 124$ & $621 \pm 348$ \\
\hline $\mathrm{I} . \mathrm{V}$ & $726 \pm 278$ & $665 \pm 249$ & $673 \pm 206$ & $691 \pm 275$ \\
\hline RV & $905 \pm 2.31$ & $814 \pm 285$ & $761 \pm 205$ & $812 \pm 445$ \\
\hline Thyroid & $673 \pm 398$ & $347 \pm 17.3 t$ & $431 \pm 317$ & $558 \pm 296$ \\
\hline
\end{tabular}

* Oxygen delivery was catculated by multiplying the appropriate arterial oxygen content ascending aortic for upper body organs: descending aortic for lower body organs) times organ blood tlow $\left(\mathrm{ml} \times \mathrm{min}^{-1} \times 100 \mathrm{~g}^{-1}\right)$. For additional information, refer to legend to lable 5 .

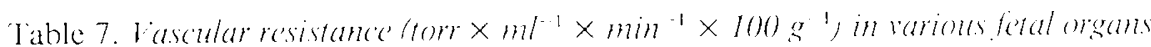

\begin{tabular}{|c|c|c|c|c|}
\hline ()rgan* & Control & Ventilation & Oxygenation & Ocolusion \\
\hline Adrenal & $0.15 \pm 0.06$ & $0.17 \pm 0.07$ & $0.3 .3 \pm 0.188$ & $(0.27 \pm 0.1$ \\
\hline Brown fat & $1.03 \pm 0.64$ & $2.24 \pm 1.81$ & $4.77 \pm 2.65 \%$ & $2.83 \pm 1.26$ \\
\hline Kidncys & $0.23 \pm 0.06$ & $0.29 \pm 0.10$ & $0.3 .3 \pm 0.11$ & $(0.36 \pm 0.12$ \\
\hline Gastrointestinal tract & $0.61 \pm 0.20$ & $1.02 \pm 0.37 \|$ & $1.21 \pm 0.70$ & $0.83 \pm 0.50$ \\
\hline Spleen & $0.17 \pm 0.08$ & $0.28 \pm 0.258$ & $0.19 \pm 0.07$ & $(0.13 \pm 0.04$ \\
\hline Periphery--lower & $3.66 \pm 0.76$ & $5.79 \pm 2.43 \$$ & $7.65 \pm 3.63$ & $6.38 \pm 2.07$ \\
\hline Periphery-upper & $3.52 \pm 0.83$ & $5.27 \pm 1.53 \|$ & $6.23 \pm 2.31$ & $5.97 \pm 1.76$ \\
\hline Brain & $0.37 \pm 0.09$ & $0.46 \pm 0.16$ & $0.95 \pm 0.35 \|$ & $0.80 \pm 0.53$ \\
\hline I.V & $0.26 \pm 0.14$ & $0.29 \pm 0.17$ & $0.54 \pm 0.20\|\|$ & $0.6 .3 \pm 0.30$ \\
\hline RV & $0.18 \pm 0.06$ & $0.21 \pm 0.07$ & $0.47 \pm 0.17 \|$ & $0.55 \pm 0.22$ \\
\hline Thyroid & $0.30 \pm 0.18$ & $0.64 \pm 0.49 \%$ & $1.15 \pm 0.94$ & $0.97 \pm 0.84$ \\
\hline
\end{tabular}

* Vascular resistances were calculated by dividing perfusion pressure (the appropriate arterial-venous values) by organ blood flow (m) $\times$ min $1 \times$ $100 \mathrm{~g}^{-1}$ ). For additional information, refer to legend to Table 5 .

following rhythmic ventilation of the lungs. oxygenation. or umbilical cord occlusion. With ventilation and oxygenation. pulmonary vascular resistance decreased and systemic vascular resistance increased: however. these changes were accompanied with only a slight decrease in pulmonary and slight increase in systemic arterial pressures. These results extend the observation. made by Dawes of al. (5) in one acutely exteriorized fetus. that an increase in femoral arterial pressure following umbilical cord occlusion occurred only after the ductus arteriosus also was ligated. Because the ductus arteriosus remained patent in our studies (17), we observed no large differences in pulmonary and systemic arterial pressures.

Upon ventilating the fetuses, we observed a bradycardia rather than the tachycardia normally observed after birth, which may have been reflex in nature. In adults. lung inflation with small transmural pressures $(<14$ torr) reflexly increases heart rate. but larger inflation pressures, in the range of pressures used in this study, reflexly decrease heart rate (20). Various cardiopulmonary reflexes are present in the developing fetus (1), and the presence of an active pulmonary stretch reflex in the fetus would aceount for the bradycardia that occurred in our study.

Rhythmic ventilation of the lungs with a gas mixture that produced no change in blood gases increased pulmonary blood flow and constricted peripheral vascular beds. Although intermittent positive pressure ventilation of anesthetized newborn rabbits decreases blood flow to the skin. muscle, ileum. and colon (20), most previous studies have demonstrated that stimulation of pulmonary stretch receptors with lung inflation stimulates a reflex vasodilatation in peripheral vascular beds in a dose-dependent manner (21).

Some of the changes in regional blood flow distribution that occurred with oxygenation can be attributed to the local effect of oxygen on certain vascular beds. The further increase in pulmonary blood flow that occurred when the FIO 2 increased from $310100 \%$ is consistent with the observations of Cassin of al. (22) in exteriorized sheep, in which expansion of the lungs with oxygen-containing gas produced a greater increase in pul- monary blood flow than did expansion with nitrogen alone However based on the results of their studies, Cassin '? al. (22) concluded that the composition of the gas. i.e. the P(). of the inspired air. was a more important determinant of pulmonary vascular tone than gascous expansion of the lungs alone. While oxygen is a potent dilator of the pulmonary vascular bed. we found that inflation of the lungs alone markedly dilated the pulmonary rascular bed. Subsequent exposure to oxygen produced an additional but smaller increase in blood flow. Blood flow to the adrenal. brain. and heart decreased with oxygenation. consistent with the local effects of oxygen on peripheral vessels (23) and with previous investigations of chronically catheteried fetal sheep (24.25). which demonstrate that adrenal. myocardial. and cerebral blood flow varies inversely with arterial oxygen content to maintain oxygen delivery at a constant level. Umbilical-placental blood flow decreased following oxygenation, perhaps as a direct response of the umbilical vasculature to increased oxygen tension $(26.27)$ although oxygen has minimal effect on umbilical-placental blood flow in acute preparations of fetal sheep (4).

Umbilical cord occlusion has been shown previousty to initiate changes important to postnatal adaptation. Padbury and colleagues (28) have shown that cutting the umbilical cord increases plasma catecholamine concentration. which results from increased adrenal medullary secretion. and increases free fatty acid mobilization and nonshivering thermogenesis (7). The increase in blood flow to the adrenal and brown fat that we observed following umbilical cord occlusion may be related to the changes observed by Padbury and colleagues (28).

Total hepatic blood flow is approximately $400(\mathrm{ml} \cdot \mathrm{min} \quad \cdot 100$ $\mathrm{g}:$ in the fetus (29) and $210-270 \mathrm{ml} \cdot \mathrm{min}^{-1} \cdot 100 \mathrm{~g}^{\prime}{ }^{\prime}$ in the newborn (30). Because the umbilical vein supplies as much as $80 \%$ of total hepatic blood flow in the fetus. portal venous and hepatic arterial blood flows increase after birth, despite the decrease in total blood flow. In our studies. umbilical cord occlusion was associated with significant increases in portal venous and hepatic arterial blood flows. These increases may 
occur in response to the cessation of umbilical venous blood flow, in a manner analogous to the increase in hepatic arterial blood flow that occurs in the adult following decreases in portal venous blood flow (31). In our studies, total hepatic blood flow following umbilical cord occlusion was $137 \pm 60 \mathrm{ml} \cdot \mathrm{min}^{-1} \cdot 100$ $g$ liver $^{-1}$, which is lower than values reported for lambs. This suggests either that the change in hepatic blood flow from fetal to newborn values may require longer than the $15 \mathrm{~min}$ we allowed before making measurements, or that some mechanism other than umbilical cord occlusion is involved.

Our previous studies have demonstrated that renal blood flow increases by about $400 \%$ between 123-133 days gestation in the fetus and 5 days of age in the newborn (32). The results from these studies show that ventilation, oxygenation, and cord occlusion are not responsible for the perinatal increase in renal blood flow. However, positive pressure ventilation decreases renal blood flow $(33,34)$ by a mechanism mediated by arterial baroreceptors and the sympathetic nervous system $(35,36)$, and it is possible that a renal vasodilatory response was masked by the vasoconstrictor effects of positive pressure ventilation. More probably, renal blood flow increases some time after the immediate perinatal period, because renal blood flow did not change during the first $6 \mathrm{~h}$ following cesarian delivery of lambs (37). Clearly, further investigation is needed to determine the control of renal blood flow in the perinatal period.

In summary, dramatic changes in the cardiovascular system at birth assist the neonate in adapting to extrauterine existence. Of the three events we investigated, ventilation, oxygenation, and umbilical cord occlusion, none could account for the differences in heart rate, arterial blood pressure, and combined ventricular output normally observed between the fetus and neonate. Ventilation and oxygenation were responsible for some of the differences in blood flow patterns between the fetus and neonate, notably an increase in pulmonary blood flow and a decrease in myocardial, cerebral, and hepatic blood flows. Future studies are needed to determine whether other perinatal events, such as prenatal increases in plasma thyroid hormone, cortisol, and catecholamine concentrations and postnatal changes in organ function, account for differences between fetal and neonatal circulation.

\section{REFERENCES}

1. Dawes GS 1961 Changes in the circulation at birth. Br Med Bull 17:148-153

2. Lister G, Walter TK, Versmold HT, Dallman PR, Rudolph AM 1979 Oxygen delivery in lambs: cardiovascular and hematologic development. Am J Physiol 237:H668-H675

3. Lucas W, Kirschbaum T, Assali NS 1966 Cephalic circulation and oxygen consumption before and after birth. Am J Physiol 210:287-292

4. Assali NS, Morris JA, Beck R 1965 Cardiovascular hemodynamics in the fetal lamb before and after lung expansion. Am J Physiol 208:122-129

5. Dawes GS, Mott JC, Widdicome JG, Wyatt DG 1953 Changes in the lungs of the new-born lamb. J Physiol (Lond) 121:141-162

6. Aperia A, Broberger O, Herin P, Joelsson 11977 Renal hemodynamics in the perinatal period. Acta Physiol Scand 99:261-269

7. Sack J, Beaudry M, DeLamater PV, Oh W, Fisher DA 1976 Umbilical cord cutting triggers hypertriiodothyroninemia and nonshivering thermogenesis in the newborn lamb. Pediatr Res 10:169-175

8. Brown MJ, Olver RE, Ramsden CA, Strang LB, Walters DV 1983 Effects of adrenaline and of spontaneous labour on the sccretion and absorption of lung liquid in the fetal lamb. $J$ Physiol (Lond) 344:137-152

9. Comline RS, Silver M 1972 The composition of foetal and maternal blood during parturition in the ewe. J Physiol (Lond) 222:233-256

10. Willis DM, Anderson DF, Thornburg KL, Faber JJ 1985 Alteration of arterial gas composition by positive pressure ventilation in the unanesthetized fetal lamb in utero. Biol Neonate 47:295-304

11. Blanco CE, Martin CB Jr, Hanson MA, McCooke H 1985 Determinants of the onset of breathing at birth. Proceedings of the 32nd Annual Meeting of the Society for Gynecological Investigation. Society of Gynecological Investigation, Phoenix, AZ, p 33

12. Gunn TR, Gluckman PD 1983 Development of temperature regulation in the fetal sheep. J Dev Physiol 5:167-179

13. Kawamura T, Gilbert RD, Power GG 1986 Effect of cooling and heating on distribution of blood flow in fetal lambs. J Dev Physiol 8:11-21

14. Kuipers JRG, Sidi D, Heymann MA, Rudolph AM 1982 Comparison of methods of measuring cardiac output in newborn lambs. Pediatr Res 16:594598

15. Heymann MA, Payne BD, Hoffman JIE, Rudolph AM 1977 Blood flow measurements with radionuclide-labeled particles. Prog Cardiovase Dis 20:55-79

16. Baer RW, Payne BD, Verrier ED, Vlahakes GJ, Molodowitch D, Uhlig PN, Hoffman JIE 1984 Increased number of myocardial blood flow measurements with radionuclide-labeled microspheres. Am J Physiol 246:H4I8$\mathrm{H} 434$

17. Teitel DF, Iwamoto HS, Rudolph AM 1987 Effects of birth events on central blood flow patterns. Pediatr Res (in press)

18. Durand DJ, Clyman RI, Heymann MA, Clements JA, Mauray F, Kitterman J, Ballard P 1985 Effects of a protein-free synthetic surfactant on survival and pulmonary function in preterm lambs. J Pediatr 107:775-780

19. Goldstein RE, Epstein SE 1970 Mechanism of elevated innominate artery pressures in supravalvular aortic stenosis. Circulation 42:23-29

20. John E, McDevitt M, Cassady G 1983 Cardiac output and organ blood flow in young rabbits during intermittent positive-pressure ventilation. Biol Neonate 44:58-64

21. Daly M deB 1986 Interactions between respiration and circulation. In: Fishman AP (ed) Handbook of Physiology, The Respiratory System II. American Physiological Society, Bethesda, MD, pp 529-594

22. Cassin S, Dawes GS, Mott JC, Ross BB, Strang LB 1964 The vascular resistance of the foetal and newly ventilated lung of the lamb. J Physiol 171:61-79

23. Sparks HV Jr 1980 Effect of local metabolic factors on vascular smooth muscle. In: Bohr DF, Somylo AP, Sparks HV Jr (eds) Handbook of Physiology, The Cardiovascular System, Vol II. American Physiological Society, Bethesda, MD, pp 475-513

24. Peeters LLH, Sheldon RE, Jones MD Jr, Makowski EL, Meschia G 1979 Blood flow to fetal organs as a function of arterial oxygen content. Am J Obstet Gynecol 135:637-646

25. Fumia FD, Edelstone DI, Holzman IR 1984 Blood flow and oxygen delivery to fetal organs as functions of fetal hematocrit. Am J Obstet Gynecol 150:274-282

26. Lewis BV 1968 The response of isolated sheep and human umbilical arteries to oxygen and drugs. J Obstet Gynaecol Br Commonw 75:87-91

27. Nyberg G, Westin B 1957 The influence of oxygen tension and some drugs on human placental vessels. Acta Physiol Scand 39:216-227

28. Agata Y, Padbury JF, Ludlow JK, Polk DH, Humme JA 1986 The effect of chemical sympathectomy on catecholamine release at birth. Pediatr Res 20:1338-1344

29. Bristow J, Rudolph AM, Itskovitz J, Barnes R 1983 Hepatic oxygen and glucose metabolism in the fetal lamb. Response to hypoxia. J Clin Invest 71:1047-1061

30. Edelstone DI, Lattanzi DR, Paulone ME, Holzman IR 1983 Neonatal intestinal oxygen consumption during arterial hypoxemia. Am J Physiol 244:G278 G283

31. Lautt WW 1981 Hepatic Circulation in Health and Disease. Raven Press, New York

32. Iwamoto HS, Oh W, Rudolph AM 1985 Renal metabolism in fetal and newborn sheep. Pediatr Res 19:641-644

33. Moore ES, Galvez MB, Paton JB, Fisher DE, Behrman RE 1974 Effects of positive pressure ventilation on intrarenal blood flow in infant primates. Pediatr Res 8:792-796

34. Gabriele G, Rosenfeld CR, Fixler DE, Wheeler JM 1977 Continuous airway pressure breathing with the headbox in the newborn lamb: effects on regional blood flows. Pediatrics 59:858-864

35. Fewell JE, Bond GC 1977 Effect of vagotomy and sinoaortic denervation on the renal response to continuous positive-pressure ventilation. Physiologist 20:29(abstr)

36. Fewell JE, Bond GC 1979 Renal denervation eliminates the renal response to continuous positive pressure ventilation. Proc Soc Exp Biol Med 161:574578

37. Breall JA, Rudolph AM, Heymann MA 1984 Role of thyroid hormone in postnatal circulatory and metabolic adjustments. J Clin Invest 73:14181424 